\title{
The State of Water in Nafion 117 of Various Cation Forms
}

\author{
Gang XIE and Tatsuhiro OKADA*
}

Received January 5, 1996 ; Accepted February 20, 1996

\begin{abstract}
The state of water in Nafion 117 membranes of various alkali and alkaline earth metal cation forms was investigated by means of differential scanning calorimetry (DSC) and infrared spectroscopy (IR). Two kinds of water molecules existed in the membranes: freezing water molecules, which interact with the metal cations and ion exchange sites weakly and could freeze at around $-20^{\circ} \mathrm{C}$, behaving in a manner close to but not identical to that of bulk water; nonfreezing water molecules which could not transfer to ice even at $-120^{\circ} \mathrm{C}$, and are considered as both the ones binding strongly with the cations and the ion exchange sites and the ones exposed to fluorocarbon environment. It was found that the fraction of freezing water of the membranes decreased with decreasing the hydrophility of the metal cations in the membranes and that the number of freezing water molecules were almost the same as that of the water molecules pumped by the cations during the cation transport. The water permeability of these membranes were measured using the streaming potential method as well. The results revealed that the water permeability increased with increasing water content of the membrane, and that the membrane equilibrated with alkali metal cations possessed a higher water permeability compared with the membrane equilibrated with alkaline earth metal cations with same water contents. The impedance measurement showed that the membrane conductivity seems to depend on both the hydrophilicity and the valence of the cations. All these results indicated that the hydrophilic domain in Nafion membranes is the determining factor for both cation and water transports in the membranes.
\end{abstract}

\section{INTRODUCTION}

Fuel cells, as systems for clean and highly efficient chemical/electrical energy conversion, are among other hottest topics these days, also in view of energy and environmental issues as backgrounds. Among various type of fuel cells, polymer electrolyte fuel cells (PEFCs) are believed as one of the most promising and practical mobile power units in the near future for their high power density and low operation temperatures ${ }^{1-3)}$. There are still many difficulties to be overcome for the development of $\mathrm{PEFCs}^{1,2,4)}$. Water

Department of Polymer Physics, National Institute of Materials and Chemical Research (Higashi 1-1, Tsukuba, Ibaraki, 305, Japan)

Key Word : Nafion, Freezing water, Water permeability, Membrane conductivity management is one of the major problems. Polymer electrolyte membranes (usually cation exchange membrane, like Nafion membrane and Dow membrane), which are used as both the diaphragm and the electrolyte in PEFCs, are high ionic conductors. However, they behave as a good proton conductor merely in the wet state and deteriorates as soon as they start to dry. To solve this problem, the understandings of ion and water transport mechanism and the quantitative information on ion and water transport behaviors in the membranes are absolutely indispensable. Transport behaviors of proton and water in Nafion 117 (Nafion is a registered trademark of Du Pont, Wilmington, DE, USA) have been studied extensively ${ }^{5-18)}$. Also structure and characteristics of Nafion membrane have 
been studied using NMR, IR and DSC 19-24). But there are very few literature ${ }^{25)}$ dealing with the detailed mechanism of water transport accompanying cation transport process in cation exchange membranes. Our research group has been focusing on the issue of water and ion transport behaviors and transport mechanisms in ion exchange membranes ${ }^{17,18,26-29)}$. In previous studies ${ }^{28,29)}$, using a new analytical procedure for accurate evaluation of water transference coefficients from streaming potential measurements, the transport behaviors of hydrophobic ammonium derivative cations with variety of sizes were investigated to find out the relationship between the water transference coefficients and the ionic size. The results were compared with the results for fully hydrophilic metal cations ${ }^{17)}$ to estimate the contribution to water transport by hydration of the cations. Based on the analysis, a model of water transport accompanying cation transport inside the ion exchange membranes were proposed: The transported water molecules are attributed to the hydrated water molecules of the transferred cations, which are almost the same as that when the cations are in bulk solution, and to the hydrodynamically "pumped" water molecules by the cations, which are proportional to the hydrated cation size due to the cation's volume exclusion effect in the narrow channel inside the membrane. In the present work, an attempt is made to obtain more information on the interactions among ions, water molecules and exchange sites and to get a better comprehension about the water transport mechanism accompanying cation transport in Nafion 117 membranes using the techniques of DSC, IR spectroscopy, impedance measurement and the streaming potential method.

\section{EXPERIMENTAL}

Solutions used in the experiments were aqueous single solutions of $\mathrm{HCl}, \mathrm{LiCl}, \mathrm{NaCl}$, $\mathrm{KCl}, \mathrm{RbCl}, \mathrm{CsCl}, \mathrm{MgCl}_{2}, \mathrm{CaCl}_{2}, \mathrm{SrCl}_{2}$, and $\mathrm{BaCl}_{2}$. All the chemicals, except $\mathrm{HCl}$, were guaranteed grade compounds (Wako
Chemical Co., Ltd., Tokyo). HCl solutions were from Merck., Titrisol ampullae, with an accuracy of $\pm 1 \%$. The concentration of all solutions was adjusted to $0.03 \mathrm{~N}$ using deionized water (conductivity $<10^{-6} \Omega^{-1} \mathrm{~cm}^{-1}$ ). The cation selective membrane, Nafion 117 as received was employed in all experiments except IR measurements. The membranes were pretreated first in $80^{\circ} \mathrm{C}$ water for $2 \mathrm{~h}$, then immersed in $0.1 \mathrm{~N} \mathrm{HCl}$ for $24 \mathrm{~h}$, and finally rinsed with pure water. Membranes were then equilibrated for at least 1 month in the appropriate solutions, prior to measurements. Solutions were replaced at least 4 times during equilibration. To determine the water content in the membrane equilibrated with various cations, membranes were taken out from the equilibration solution, then lightly wiped with filter paper to remove excess surface water, and quickly weighed by a microbalance. Membranes were then dried completely by: drying at ambient temperature for $24 \mathrm{~h}$ under vacuum followed by heating under vacuum at $110^{\circ} \mathrm{C}$ for $12 \mathrm{~h}$. Membranes were weighed, and from the difference in the weight in wet and dry states, water content $\lambda$ was obtained as number of water molecules per cationic site $\mathrm{H}_{2} \mathrm{O} / \mathrm{SO}_{3}$.

A Seiko Co., Ltd. differential scanning calorimeter DSC 220C was used to measure the phase transition of water sorbed in the membranes. DSC curves were obtained by cooling from room temperature to $-120^{\circ} \mathrm{C}$ at the scanning rate of $1^{\circ} \mathrm{C} / \mathrm{min}$. The membranes were sealed in aluminum pans to prevent evaporation during the measurement The area under freezing peak was measured, and the amount of freezing water was computed according to the enthalpy of possible polymorphism of ice. The amount of nonfreezing water was taken as the difference between the total water content in the membrane and the amount of freezing water.

IR spectroscopes were measured using a Japan Spectroscopic Co., Ltd. A-3 model infrared spectrometer in order to get information on the effects of counterion type and degree of hydration upon the exchange 
sites inside the membranes of various cation forms. The samples for IR measurements were prepared by dissolving Nafion 117 into an ethanol-water(50:50) mixture at $230^{\circ} \mathrm{C}$ at around 40 atms and recasting it using $\mathrm{N}, \mathrm{N}^{\prime}$ dimethylformamide (DMF) to membranes of $20 \mu \mathrm{m}$ in thickness ${ }^{30}$. A comparison of membrane water contents between the recast membrane and the as received form Nafion 117 indicated that there was no significant difference in hydrated states of these two kinds of membranes.

The water permeability $L_{\mathrm{p}}$ of the membranes of various cation forms, which gives the hydrodynamic flow of water induced by a unit pressure difference across the membrane, were measured using the streaming potential method $\left(L_{p}=J_{v} / \Delta p\right.$, where $J_{v}$ and $\Delta p$ are volume flux and pressure difference over the membrane, respectively). Note that this value is different from the water transference coefficient, which expresses the number of moles of water accompanying the flow of one Faraday of charge across the membrane. The theory and procedure for streaming potential measurements and the experimental apparatus were described previously ${ }^{17,26)}$.

Membrane conductivity were determined using impedance measurement method Impedance measurements were carried out with a Solartron 1260 frequency response analyzer (Solartron Instruments, England) which was controlled via a personal computer. A $20 \mathrm{mV}$ peak-to-peak ac. signal over the frequency range $10^{7}-10^{-3} \mathrm{~Hz}$ was superimposed across the cell upon the equilibrium cell potential. The cell for the measurement was something similar to that used by Zawodzinski et a/12) except that we utilized a pair of platinized platinum electrodes. The sketch of the cell is shown in Fig. 1. The two windows were filled with the solution, with which the sample membrane was equilibrated, to prevent the drying of the membrane during measurements.

\section{RESULTS AND DISCUSSION}

The DSC curves of the membranes of

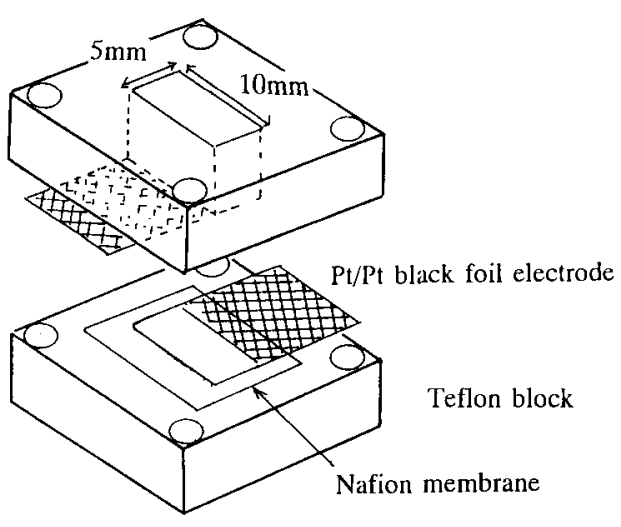

Fig. 1 A schematic of the cell for membrane impedance measurements.

various cation forms are shown in Figs. 2 and 3. Actually, the membranes were cooled to $-120^{\circ} \mathrm{C}$, but no peak appeared except that observed in the temperature range from -30 to $30^{\circ} \mathrm{C}$. The temperature of freezing of adsorbed water were calibrated using pure water (deionized distilled water) Considering that the thermogram has not been normalized by the sample weight in Figs 2 and 3, a direct comparison of melting heat among the samples cannot be made from these figures. However, it does not affect any of the arguments and conclusions given below. The water content of the membranes were determined separately in the previous study ${ }^{17)}$ and are cited in Table 1. In the case of the membranes of alkali metal cation forms, freezing peaks appears at around -13 to $-20^{\circ} \mathrm{C}$, this freezing temperature is lower than that of pure water. Some of the freezing peaks of the membranes were split As the cation hydrophilicity (i.e., affinities to water molecules, and can be roughly considered as the membrane water content here) decreases, the freezing peaks are shifted to much lower temperatures, and become as well-defined ones. For the membranes of the alkaline earth metal cation forms, the tendency is similar to that observed above except that all the 


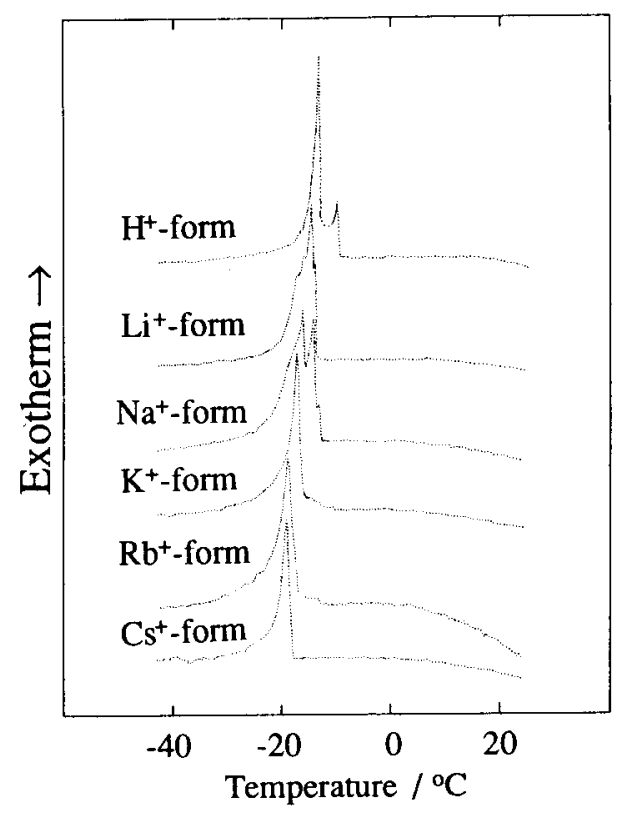

Fig. 2 DSC curves of Nafion 117 membranes of $\mathrm{H}^{+}$and alkali metal cation forms.

freezing peaks of the membranes were split The crosslink effects (i.e., an alkaline earth metal cation interacts with two ion exchange sites) in these membranes may complicate the interaction among the water molecules, the cations and the exchange sites. Three conclusions could be reached according to the above results. Firstly, completely free water molecules (bulk water) did not exist in the membranes probed; Secondarily, the split freezing peaks maybe indicate the existence of several kinds of water molecules in different states in the membrane. Finally, it seems that the interactions between the absorbed water and the environments

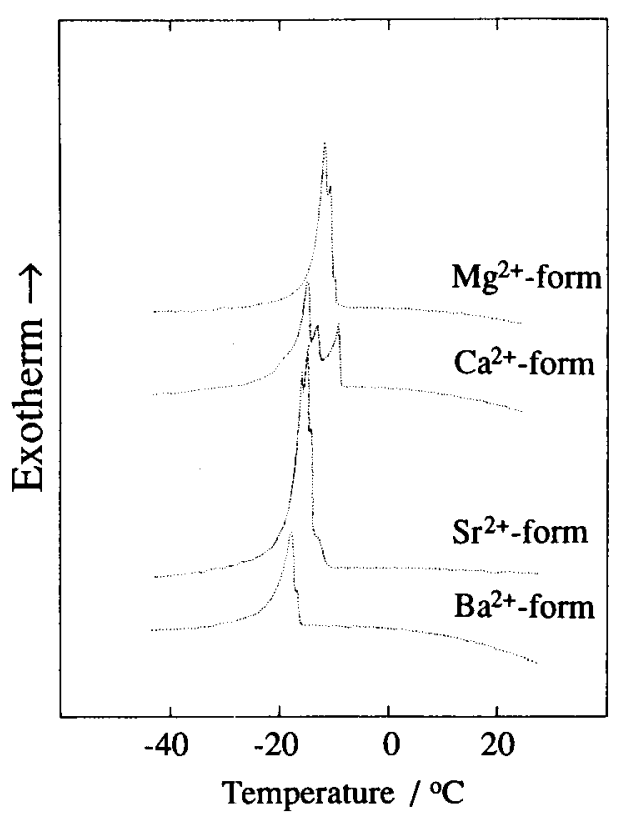

Fig. 3 DSC curves of Nafion 117 membranes of alkaline earth metal cation forms

increase with decreasing hydrophilicity of the cation.

Freezing water must have certain kinds of crystalline structure which may be the same as the structure of natural ice, regardless of the crystalline morphism. There are nine polymorphic forms of ice: I, Ic, II , III , IV, V, VI, VII and VIII1). The structures of ice from IV to VIII are formed only at very high pressures. Therefore, in the present experimental conditions the possible structure of ice for freezing water can be considered as ice I, Ic, II or III. The maximum and the minimum values of melting enthalpy of them are 334 (ice I) and $311 \mathrm{~J} / \mathrm{g}$

Table 1 The results of DSC and the streaming potential measurements ${ }^{17,28,29}$ ) for the Nafion 117 membranes of various cation forms.

\begin{tabular}{|c|c|c|c|c|c|c|c|c|c|c|}
\hline Membrane form & $\mathrm{H}^{+}$ & $\mathrm{Li}^{+}$ & $\mathrm{Na}^{+}$ & $\mathrm{K}^{+}$ & $\mathrm{Rb}^{+}$ & $\mathrm{Cs}^{+}$ & $\mathrm{Mg}^{2+}$ & $\mathrm{Ca}^{2+}$ & $\mathrm{Sr}^{2+}$ & $\mathrm{Ba}^{2+}$ \\
\hline Water content $\lambda / \mathrm{H}_{2} \mathrm{O}^{-} \mathrm{SO}_{3}$ & 22.6 & 19.5 & 16.5 & 10.8 & 10.1 & 8.6 & 17.3 & 17.2 & 16.2 & 14.1 \\
\hline Freezing water $/ \mathrm{H}_{2} \mathrm{O}_{3} \mathrm{SO}_{3}$ & $9.9 \sim 10.6$ & $8.7-9.3$ & $7.4 \sim 7.8$ & $4.3 \sim 4.5$ & $2.9 \sim 3.1$ & $3.3 \sim 3.5$ & $8.3 \sim 8.9$ & $7.5 \sim 8.0$ & $7.2 \sim 7.6$ & $4.3 \sim 4.6$ \\
\hline $\mathrm{t}_{\mathrm{H} 2 \mathrm{O}}$ (pump) & no data & 10.2 & 6.9 & 3.9 & 4.3 & 5.4 & no data & no data & no data & no data \\
\hline
\end{tabular}


(ice III), respectively. The content of freezing water was calculated from the area of the freezing peak of water in the DSC curves using melting enthalpy of both ice I and III . The results are tabulated in Table 1 as well. For further analysis, some results of the streaming potential measurements ${ }^{17,28,29)}$ are cited here. Obviously, the number of freezing water molecules is smaller than that of the total water molecules absorbed in the membranes. That is, freezing water merely occupies a part of the water absorbed in the membranes, and the rest of the water (usually called nonfreezing water) can not transfer to ice even at $-120^{\circ} \mathrm{C}$. Since the samples were sealed in aluminum pans and the start temperature was low (room temperature), evaporation of water absorbed in the membranes could be ignored. Therefore, nonfreezing water molecules must involve the ones which are strongly bound with the cations or the cation exchange sites. The amount of nonfreezing water was then taken as the difference between the total water content in the membrane and the amount of freezing water.

From Table 1, it can be seen that the ratio of freezing water in the membranes to the total water content decreases with decreasing hydrophilicity of the cations. The possible explanations might be either that the fraction of water bound strongly with the ion exchange sites (sulfonate group) is increasing with decreasing hydrophilicity of the cations, i.e., the hydration of the ion exchange sites is affected by the type of the cation, or that the fraction of water located in the interfacial region between hydrophilic and hydrophobic domains in the membrane is increasing with decreasing hydrophilicity of the cations.

A more intriguing fact is that the number of freezing water in the membranes is almost the same as that pumped by the cations during the cation transport process. It then could be concluded that the cations would pump all the water molecules except that bound strongly with exchange sites and the cations. This could occur only in such a situation that the channel which the cations pass through is so narrow that the cations would expel all the obstacles, i.e., the freezing water molecules, which are relatively mobile, on their way. Actually, in a previous study ${ }^{17)}$, the effective pore diameter in Nafion 117 membranes was estimated to be about $1 \mathrm{~nm}$ depending on the hydrophilicity of the cations.

The IR spectrum of the membranes are collected for the specially prepared thin membranes. The two bands which should provide the most useful information concerning the effects of environment on the ion exchange properties of the membrane are the symmetric stretches of free $\mathrm{OH}$-group and that of OH-group connected by hydrogen bonds at around 3615 and 3450 $\mathrm{cm}^{-1}$, respectively ${ }^{32}$ ). The following analysis are mainly based on these two bands.

Figures 4 and 5 show the spectral region of around 3615 and $3450 \mathrm{~cm}^{-1}$ band of the membranes of various cation forms. The IR spectra of the membranes show a broad absorption band at around $3450 \mathrm{~cm}^{-1}$, which is assigned to the stretching oscillations of OH-groups connected by hydrogen bonds. The fact that there is no absorption peak (or shoulder) at $3615 \mathrm{~cm}^{-1}$ suggests the absence

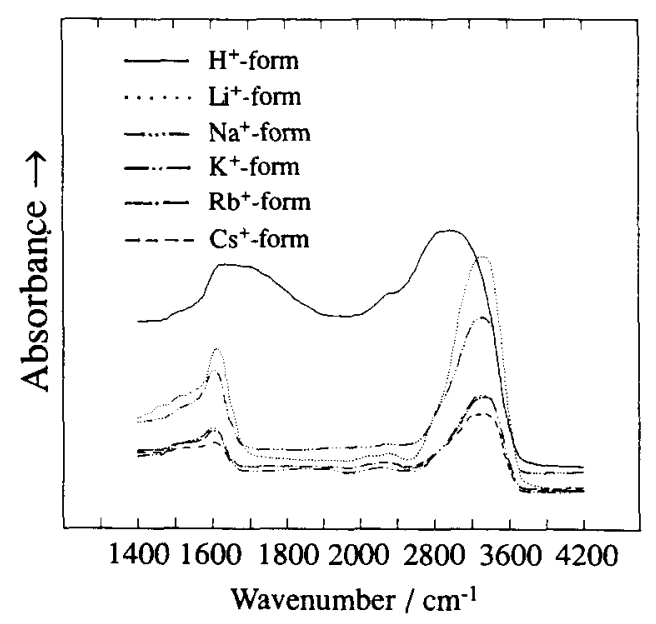

Fig.4 IR spectra of Nafion 117 membranes of $\mathrm{H}^{+}$and alkali metal cation forms. 


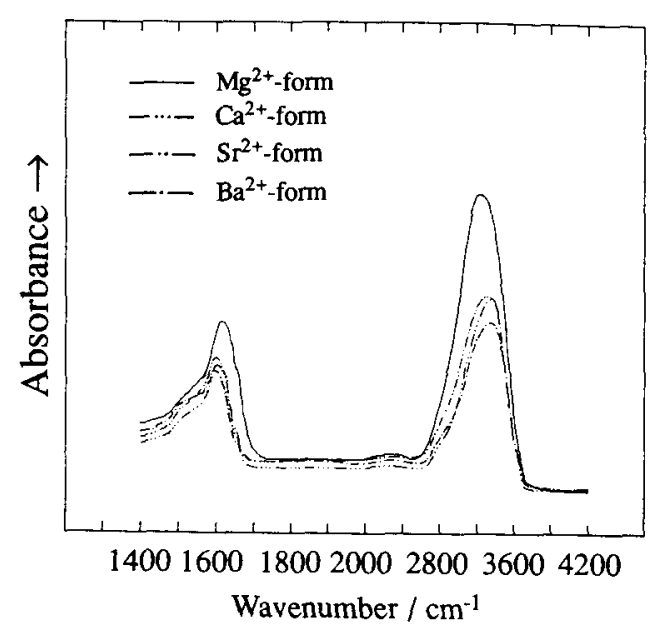

Fig.5 IR spectra of Nafion 117 membranes of alkaline earth metal cation forms.

of water molecules with completely free $\mathrm{OH}$ groups

The above results could give a model for the states of water in the membranes probed. Nonfreezing water, which is not revealed in the DSC curves, involves either bound water in primary hydration shells of cations and sulfonic groups (i.e., primary hydration group) or unbound water at phase boundaries near hydrophobic domains (i.e., interfacial region group). Freezing water refers to the weakly bound water, which is involved in secondary or higher order hydration shells (i.e., high order hydration group). They are close to but not identical to bulk water and freezes at temperature below the freezing point of bulk water. However, the existence of solvation group, which remains unaffected under the action of ionic, polar group and hydrophobic environment, with the freezing point of $0^{\circ} \mathrm{C}$, could hardly be observed.

In order to better understand the effect of counterion type on the water transport process, the water permeability (pore fluid flow) of the membranes of various cations forms were measured using the streaming potential method and are plotted against the membrane water content $\lambda$ in Fig. 6 . It can be

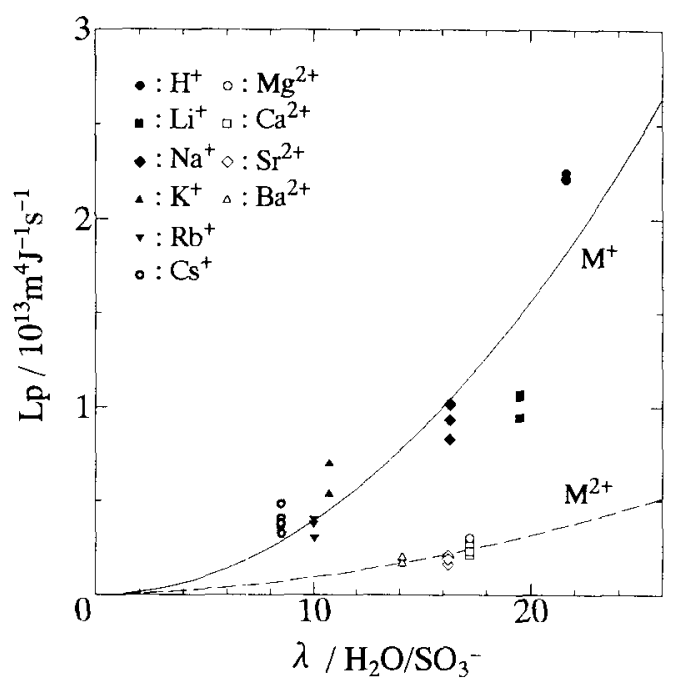

Fig.6 Water permeability of Nafion 117 membranes of various cation forms against membrane water content $\lambda$.

seen that these two factors are mutually correlated: the water permeability of the membrane increases with increasing membrane water content. The hydrophilic domains in the membrane increases as the water content of the membrane increases. This leads to the increase in the pass of water inside the membrane, and therefore to the increase in the water permeability. In addition, It is obvious that the membrane of alkaline earth metal cation form possesses a smaller water permeability compared to that of alkali metal cation form with same water content Alkaline earth metal cations can bind up to two sulfonic acid groups and thereby may crosslink the conducting channels. Crosslink prevents the movements of water molecules in the membrane, and as a consequence, reduce the water permeability.

The influence of the degree of hydration and the effect of counterion type on ion transport, i.e., the membrane conductivity was investigated as well using impedance measurement method. The results are plotted against the membrane water content $\lambda$ in Fig.7. The membrane conductivity and the membrane water content are obviously related 


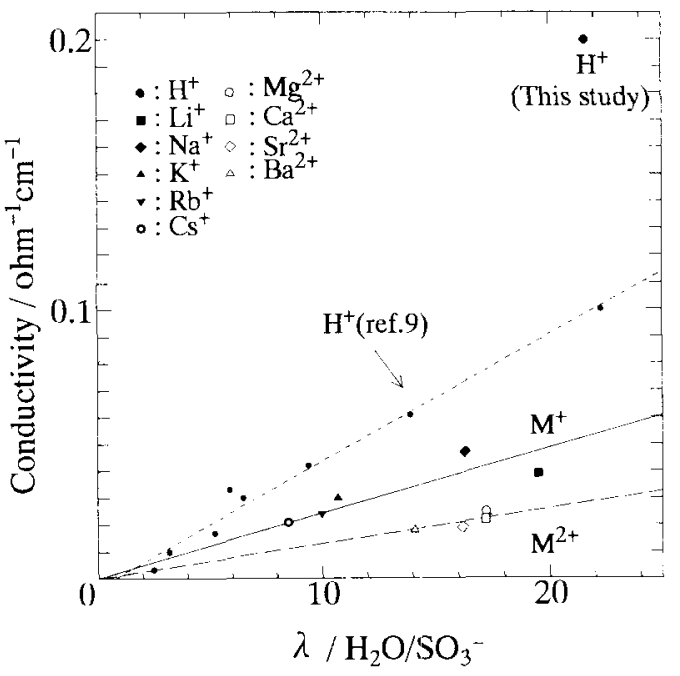

Fig. 7 Ionic conductivity of Nafion 117 membranes against membrane water content.

The membrane conductivity depends on both the hydrophilicity and the valence of the cations. For the cations with same valence, the membrane conductivity increases with increasing membrane water content in the same manner irrespective the type of counterion except that of the $\mathrm{H}^{+}$-form membrane. These tendencies are opposite to those observed in aqueous solutions ${ }^{33 \text { ) }}$ as can be seen from Fig. 8 . In the case of aqueous solutions, the paths for the cations transport are infinite and free, and the predominant factor which determines the speed of the cations transport is the size of the hydrated cations themselves. In the case of membranes, it seems that the largeness of hydrophilic domain together with the size of the cations is the determining factor for cation transport. The $\mathrm{H}^{+}$-form membrane possesses a extremely high conductivity compared with the others, perhaps due to its special transport mechanism, i.e., the hopping transport mechanism. A set of data of $\mathrm{H}^{+}$-form membrane conductivity as a function of the membrane water content have been reported by Zawodzinski et $a^{(9)}$ and are replotted in Fig. 7 as well. Their data also revealed that the transport behavior of proton is distinct from that of other univalent

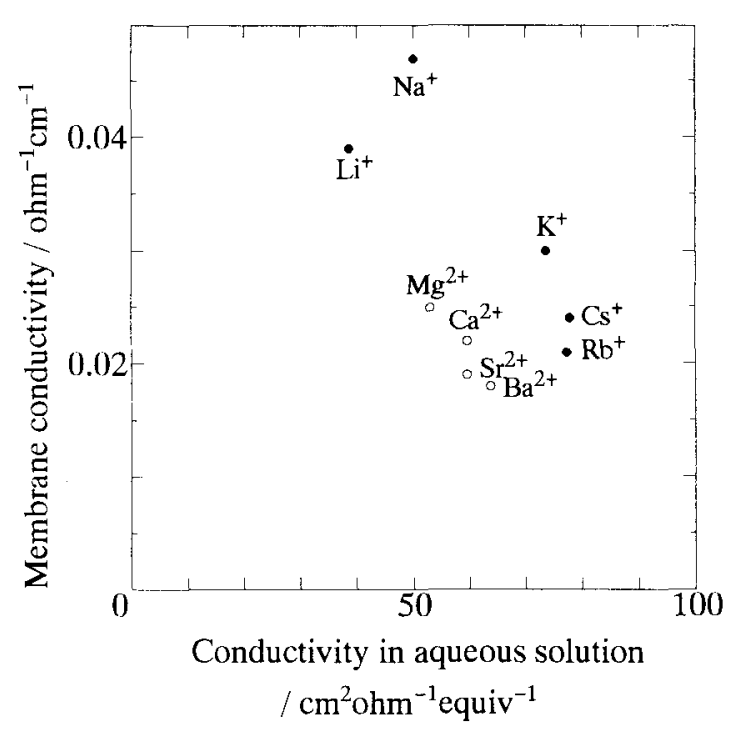

Fig. 8 A comparison between ionic conductivity of cations in Nafion membrane and in infinite dilute aqueous solutions.

cations. As can be expected, the membrane conductivity of alkaline earth metal cation form is lower than that of alkali metal cation form with same water content. The higher the cation charge density, the stronger will be the interaction between the cation and the membrane ion exchange site. Besides, crosslink effect of the alkaline earth metal cation with the membrane may also be a factor obstructing the movement of the cation itself in the membrane

\section{CONCLUSION}

The state of water in Nafion 117 membranes of various alkali and alkaline earth metal cation forms was investigated by means of DSC and IR spectroscopy. It was found that nonfreezing water involves bound water in primary hydration shells of cations and that to sulfonic groups or unbound water at phase boundaries near hydrophobic domains. Freezing water refers to the weakly bound water, which is involved in secondary and higher order hydration shells and freezes at temperature below the freezing point of bulk water. The result that the number of 
freezing water is almost the same as that pumped by the cations during the cation transport process suggests that the channel which cations pass through is very narrow. The water permeability of the membrane increases with increasing cation hydrophilicity and is reduced by crosslink effect. The membrane conductivity seems to depend on both the hydrophilicity and the valence of the cations. Among them, the $\mathrm{H}^{+}$-form membrane possesses a high conductivity compared with the others, perhaps due to proton's special hopping transport mechanism. All these results indicated that the hydrophilic domain in Nafion membranes is the determining factor for both cation and water transports in the membranes.

This study has been supported by Research Development Corporation of Japan and National Institute of Materials and Chemical Research. The authors thank Dr. Tomoaki Arimura from Japan Vilene Co., Ltd. for preparation of the recast Nafion membrane for IR measurements and his useful advice.

\section{REFERENCES}

1) S. Srinivasan, J. Electrochem. Soc., 136, 41c(1989).

2) D. J. Manko, H. Koch, M. A. Enayetullah and A. J. Appleby, J. Power Sources, 29, 367(1990).

3) G. A. Eisman, J. Power Sources, 29, 389 (1990).

4) Y. W. Rho, S. Srinivasan and Y. T. Kho, J. Electrochem. Soc., 136, 2089(1994).

5) J.L.Fales, N.E. Vanderborgh and P.Stroeve, Diaphragms, Separators, and IonExchange Membranes, (Ed. J.W. Van Zee, R. E.White, K.Kinoshita and H.S.Burney), PV 86-13, p.179, The Electrochemical Society Softbound Proceedings Series, Pennington, NJ(1986)

6) A.B.LaConti, A.R.Fragala and J.R.Boyack, Proceedingsof the SymposiumonElectrode Materials and Processes for Energy Conversion and Storage, (Ed. J. D. E. McIntyre, S.Srinivasan and F.G.Will), PV $77-6$, p.354, The Electrochemical Society
Softbound Proceedings Series, Princeton, NJ(1977).

7) T. A. Zawodzinski, Jr., T. E. Springer, J. Davey, J. Valerio, and S. Gottesfeld, Proceeding of The Sympsium On Modeling of Batteries And Fuel Cell, (Ed R. E. White, M. W. Verbrugge, and J. F. Stockel), PV 91-10, p187, The Electrochemical Society Softbound Proceedings Series, Pennington, NJ(1991)

8) T. E. Springer, T. A. Zawodzinski, and S. Gottesfeld, J. Electrochem. Soc., 138,2334 (1991).

9) T. A. Zawodzinski, Jr., C. Derouin, S. Radzinski, R.J.Sherman, V.T.Smith, T.E. Springer, and S. Gottesfeld, J. Electrochem. Soc., 140,1041(1993)

10) T. A. Zawodzinski, Jr., T. E. Springer, J.Davey, R.Jestel, C.Lopez, J.Valerio, and S. Gottesfeld, J. Electrochem. Soc., 140, 1981(1993).

11) T.F.Fuller and J.Newman, J. Electrochem. Soc., 139,1332(1992)

12) T. A. Zawodzinski, Jr., M. Neeman, L.O. Sillerud and S.Gottesfeld, J. Phys. Chem., 95,6040(1991).

13) M.Wakizoe, O.A.Velev, and S.Srinivasan, Electrochimica Acta, 40,335(1995)

14) T.A.Zawodzinski, J.Davey, J.Valerio, and S. Gottesfeld, Electrochimica Acta, 40,335 (1995).

15) M. G. McLin, M. C. Wintersgill and S. G. Greenbaum, J. Solid State Ionics, 60, 137 (1993).

16) R. S. Chen, P. E. Stallworth, S. G. Greenbaum, J. J. Fontanella and M. C. Wintersgill, Electrochimica Acta, 40, 335 (1995)

17) G.Xie and T.Okada, J. Electrochem. Soc., 142,3057(1995).

18) T.Okada, G.Xie and Y.Tanabe, submitted to J. Electroanal. Chem.

19) R.S.Chen, J.P.Jayakody, S.G.Greenbaum, Y. S. Pak, G. Xu, M. G. McLin and J. J Fontanella, J. Electrochem. Soc., 140, 889 (1993)

20) T. A. Zawodzinski, Jr., M. Neeman, L.O. Sillerud and S.Gottesfeld, J. Phys. Chem., 95,6040(1991). 
21) M. Falk, Can. J. Chem., 1980,58,1495.

22) S. R. Lowry and K. A. Mauritz, J. Am. Chem. Soc., 102,4665(1980)

23) R.Buzzoni, S.Bordiga, G.Ricchiardi, G Spoto and A.Zecchina, J. Phys. Chem., 99,11937(1995).

24) M.Tasaka, S.Suzuki, Y.Ogawa and M. Kamaya, J. Membr. Sci. 38,175(1988).

25) B. R. Breslau and I. F. Miller, Ind. Eng. Chem. Fundam., 10,554(1971).

26) T. Okada, S. K. Ratkje and H. HancheOlsen, J. Membr. Sci. 66,179(1992).

27) T Okada, S. K. Ratkje, L.O.Jerdal, K. Friestad, G.Xie and R.Holmen, J. Membr. Sci., in press.

28) G. Xie and T. Okada, Electrochimica Acta, in press.

29) G. Xie and T. Okada, J. Chem. Soc., Faraday Transactions, in press.

30) R. B. Moore, III and C. R. Martin, Anal. Chem., 58,2569(1986).

31) D. Eisenberg and W. Kauzmann, The Structure and Properties of Water, Oxford University Press, London(1969).

32) G Zundel, Hydration and Intermolecular Interaction, Academic, NY(1969).

33) R. A. Robinson and R. H. Stokes, Electrolyte solutions, Butterworths, London(1965). 